\title{
Prominent contribution of portal mesenchymal cells to liver fibrosis in ischemic and obstructive cholestatic injuries
}

\author{
Marc Beaussier ${ }^{1,2,3}$, Dominique Wendum ${ }^{4}$, Eduardo Schiffer ${ }^{5}$, Sylvie Dumont ${ }^{4,6}$, Colette Rey ${ }^{1,2}$, André Lienhart ${ }^{3}$ \\ and Chantal Housset ${ }^{1,2,7}$
}

Liver fibrosis is produced by myofibroblasts of different origins. In culture models, rat myofibroblasts derived from hepatic stellate cells (HSCs) and from periductal portal mesenchymal cells, show distinct proliferative and immunophenotypic evolutive profiles, in particular regarding desmin microfilament (overexpressed vs shut-down, respectively). Here, we examined the contributions of both cell types, in two rat models of cholestatic injury, arterial liver ischemia and bile duct ligation (BDL). Serum and (immuno)histochemical hepatic analyses were performed at different time points ( 2 days, 1 , 2 and 6 weeks) after injury induction. Cholestatic liver injury, as attested by serum biochemical tests, was moderate/ resolutive in ischemia vs severe and sustained in BDL. Spatio-temporal and morphometric analyses of cytokeratin-19 and Sirius red stainings showed that in both models, fibrosis accumulated around reactive bile ductules, with a significant correlation between the progression rates of fibrosis and of the ductular reaction (both higher in BDL). After 6 weeks, fibrosis was stabilized and did not exceed F2 (METAVIR) in arterial ischemia, whereas micronodular cirrhosis (F4) was established in BDL. Immuno-analyses of $\alpha$-smooth muscle actin and desmin expression profiles showed that intralobular HSCs underwent early phenotypic changes marked by desmin overexpression in both models and that the accumulation of fibrosis coincided with that of $\alpha$-SMA-labeled myofibroblasts around portal/septal ductular structures. With the exception of desmin-positive myofibroblasts located at the portal/septal-lobular interface at early stages, and of myofibroblastic HSCs detected together with fine lobular septa in BDL cirrhotic liver, the vast majority of myofibroblasts were desmin-negative. These findings suggest that both in resolutive and sustained cholestatic injury, fibrosis is produced by myofibroblasts that derive predominantly from portal/periportal mesenchymal cells. While HSCs massively undergo phenotypic changes marked by desmin overexpression, a minority fully converts into matrix-producing myofibroblasts, at sites, which however may be important in the healing process that circumscribes wounded hepatocytes.

Laboratory Investigation (2007) 87, 292-303. doi:10.1038/labinvest.3700513; published online 29 January 2007

KEYWORDS: bile duct ligation; cholestasis; hepatic stellate cell; liver fibrosis; liver ischemia; liver myofibroblast

Following repeated injury, the liver undergoes a tissue remodeling process that combines regeneration and fibrogenesis. In this repair process, extracellular matrix is produced in excess by smooth muscle $\alpha$-actin $(\alpha$-SMA) immunoreactive cells called myofibroblasts, the origin(s) of which remain(s) enigmatic. A very large number of studies indicate that myofibroblasts may derive from hepatic stellate cells (HSCs), that is vitamin A-storing cells with long cytoplasmic processes that, in the normal liver, reside in the perisinusoidal space of Disse. ${ }^{1,2}$ The ability of HSCs to differentiate into myofibroblasts was first demonstrated in culture, over 20 years ago. ${ }^{3-5}$ It was subsequently shown that these cells were able to acquire features of a myofibroblastic phenotype in response to liver injury in vivo, based on the analyses of HSCs that were isolated from injured rat livers. ${ }^{6,7}$ In addition, transitional cells that are intermediate between HSCs and myofibroblasts have been detected by in situ analyses of fibrotic livers. ${ }^{8-10}$ Other mesenchymal cells, distinct from HSCs, may however also convert into myofibroblastic cells during liver fibrogenesis. ${ }^{11}$ There is evidence, in particular, to

${ }^{1}$ Inserm, U680, Paris, France; ${ }^{2}$ Faculté de Médecine, Université Pierre et Marie Curie-Paris 6, Paris, France; ${ }^{3}$ Département d'Anesthésie-Réanimation Chirurgicale, AP-HP, Hôpital Saint-Antoine, Paris, France; ${ }^{4}$ Service d'Anatomie Pathologique, AP-HP, Hôpital Saint-Antoine, Paris, France; ${ }^{5}$ Département d'Anesthésie-Réanimation APSIC, Hôpital Universitaire de Genève, Genève, Suisse; ${ }^{6}$ Inserm, IFR65, Paris, France and ${ }^{7}$ Service de Biochimie et d'Hormonologie, AP-HP, Hôpital Tenon, Paris, France Correspondence: Dr C Housset, MD, PhD, Inserm U680, Faculté de Médecine Pierre et Marie Curie, Site Saint-Antoine, 27, rue Chaligny, 75571 Paris Cedex 12, France. E-mail: chantal.housset@st-antoine.inserm.fr

Received 13 September 2006; revised 13 November 2006; accepted 14 November 2006 
indicate that mesenchymal cells in the portal tract, which include fibroblasts located around bile ducts ${ }^{11}$ give rise to myofibroblasts in biliary-type liver fibrosis. ${ }^{12-17}$ As the portal area is a prominent location of fibrosis development not only in biliary diseases, but in virtually all types of chronic liver diseases, including viral and alcohol-related diseases, ${ }^{18,19}$ the implication of portal mesenchymal cells in the formation of liver fibrosis may be more important than what has been generally assumed. However, no marker(s) has been identified that allows, so far, to fully discriminate these cells from HSCs at the stage of myofibroblasts, ${ }^{14,20-23}$ and to what extent these cells compared with HSCs may actually contribute to liver fibrogenesis is at present largely unknown.

We and others described previously a method to obtain cultures of peribiliary myofibroblasts, by outgrowth of portal mesenchymal cells from rat bile duct preparations. ${ }^{14,16}$ In comparing, these cells with myofibroblasts derived from rat HSCs in culture, we consistently observed higher proliferation rates and a distinct evolutive profile of desmin expression. In peribiliary myofibroblasts, desmin immunoreactivity gradually decreased over time, so that after four passages, at least $80 \%$ of the cells (all $\alpha$-SMA-positive) were desminnegative. ${ }^{16}$ Likewise, Knittel et $a l^{21}$ reported that rat liver myofibroblasts obtained in culture by outgrowth from a fraction of nonparenchymal liver cells, were much more proliferative and resistant to apoptosis than HSCs, and that at least $87 \%$ of these myofibroblastic cells from passages 1-6 were desmin-negative. In HSCs, by contrast, desmin overexpression has been identified as a constant and early feature of the phenotypic changes induced either by culture activation or by liver injury in vivo, ${ }^{7,16,24,25}$ and we previously found that $100 \%$ of myofibroblasts derived from HSCs exhibit a strong reactivity for desmin, whatever the time in culture. $^{16}$

In the present study, we investigated the wound healing response to cholestatic liver injury, in two experimental models of self-limited and persistent injury, ie arterial liver ischemia ${ }^{26}$ and bile duct ligation (BDL), ${ }^{27}$ respectively. In these two different models, we determined by morphometric and spatio-temporal analyses, the progression rates of fibrosis and its relationship with ductular reaction. In parallel, we examined the evolutive profiles of $\alpha$-SMA and desmin expression, to appraise the relative contributions of HSC and of other, primarily portal, mesenchymal cells to fibrosis, in the two types of response.

\section{MATERIALS AND METHODS} Animal Models

Male Wistar rats (Elevage Janvier, Le Genest St Isle, France) weighing 300-400 g at the time of surgery were kept under a 12-h light-dark cycle and allowed free access to water and standard rat chow. Experiments were performed in compliance with the national ethical guidelines for the care and use of laboratory animals. The animals were anesthetized with a subcutaneous injection of chlorpromazine $(2 \mathrm{mg} / \mathrm{kg})$ and ketamine $(20 \mathrm{mg} / \mathrm{kg})$. Appropriate depth of anesthesia was ascertained by the absence of corneal reaction after tactile stimulation.

In the first model of liver injury, that is arterial liver ischemia, complete arterial deprivation of the liver was achieved as previously described. ${ }^{26}$ Briefly, in a first step, the liver was prepared as for graft removal during liver transplantation. ${ }^{28}$ At the completion of this procedure, the liver was isolated from all peripheral vascular supply except for the main hepatic artery, the extrahepatic peribiliary plexus and the portal vein. In what was defined as Sham operation, no additional vascular interruption was performed. For complete arterial deprivation, the animals further underwent double ligation-division of the main hepatic artery and double ligation of the extrahepatic peribiliary vascular plexus. To interrupt the peribiliary vasculature without compromising bile flow, the common bile duct was cannulated with a polyethylene cuff $(\sim 3-\mathrm{mm}$ length, $0.3-\mathrm{mm}$ inside diameter), which was then secured with two circumferential $6 / 0$ silks. In the second model of liver injury, that is BDL, double ligation and section of the common bile duct was performed, as originally described by Kountouras et al. ${ }^{27}$ Here, Sham operation consisted in laparotomy and bile duct exposure without ligation.

Each experimental group, comprised (besides Shamoperated rats) 16 animals, four of which underwent liver ablation under anesthesia for (immuno)histochemical analyses on postoperative day 2 , week 1 , week 2 and week 6 . At each time point, blood was withdrawn from the aorta, and serum concentrations of total bilirubin, $\gamma$-glutamyl transpeptidase, alkaline phosphatase, aspartate aminotransferase, and alanine aminotransferase, were measured using standard analytical methods.

\section{(Immuno)histochemistry}

Immediately after ablation of the liver, liver tissue samples were fixed in $10 \%$ formalin and embedded in paraffin. Serial $4-\mu \mathrm{m}$-thick liver tissue sections were deparaffinized and submitted to Sirius red or immunohistochemical stainings. For immunohistochemistry the following mouse monoclonal antibodies were used as primary antibodies: anti-cytokeratin 19 (NCL-CK19, Novocastra, Newcastle, UK, 1/100, $18 \mathrm{~h}$ at $4^{\circ} \mathrm{C}$ ); anti- $\alpha$-SMA (Dako, M851, 1/100, $30 \mathrm{~min}$ at room temperature); anti-desmin (Dako, Trappes, France), M760, $1 / 20,30 \mathrm{~min}$ at room temperature). Trypsin digestion $\left(30 \mathrm{~min}\right.$ at $\left.37^{\circ} \mathrm{C}\right)$ and microwave antigen retrieval were accomplished before immunohistochemical labeling for cytokeratin 19 (CK19) and desmin, respectively. Immunolabeling was achieved using a Super Sensitive Link-label Immunohistochemistry Detection System (Biogenex, San Ramon, CA, USA). First, tissue sections were incubated with $0.1 \%$ hydrogen peroxide in methanol for $30 \mathrm{~min}$ to inhibit endogenous peroxidase activity, and in solutions of avidin $\mathrm{D}$ (15 min) and of biotin ( $15 \mathrm{~min})$ to prevent nonspecific binding, using an avidin/biotin blocking kit (Vector 
Laboratories, Burlingame, CA, USA). Then, tissue sections were incubated successively with the primary antibodies as defined above, with biotinylated anti-immunoglobulins for $20 \mathrm{~min}$, and with horseradish peroxidase-labeled streptavidin for $20 \mathrm{~min}$. Peroxidase activity was revealed by incubation with 3-amino-9-ethylcarbazole solution, and tissue sections were counterstained with hematoxylin. Controls obtained by omitting the primary antibodies were all negative.

\section{Analyses of (Immuno)histochemical Stainings}

Sirius red, CK19, $\alpha$-SMA and desmin (immuno)stainings were quantified by morphometric analyses, using a computerized image analysis system (Leica Q500 IW, Leica microsystem, Rueil Malmaison, France). Labeled areas in blinded specimens were measured at a video screen display magnification of $\times 100$ and expressed as the ratio of labeled area per total analyzed field surface. The average of the score taken from 10 consecutive fields of $0.6 \mathrm{~mm}^{2}$ centered on a portal tract, was used to generate a single score for each specimen.In addition, the topographic distribution of $\alpha$-SMA and/or desmin immunoreactive cells, was assessed by semi-quantitative analysis. Three compartments were distinguished, as previously proposed: ${ }^{22}$ within hepatic sinusoids in the lobule, called lobular; within portal tracts or fibrotic septa, called portal/septal; at the interface of portal tracts or fibrotic septa with the liver parenchyma. A relative score was attributed to the proportion of immunoreactive cells for one marker in each compartment, as follows: - , no or very rare cells; + , minor, ++ , medium, +++ , major proportions of cells. Immunoreactivities present in blood vessels, which were automatically included in the morphometric analyses, were excluded from these topographic analyses.

The terminology used to designate biliary structures is based on the consensus published by Roskams et al. ${ }^{29}$ Accordingly, bile ducts are defined as the biliary structures positioned centrally in the portal tract adjacent to arterioles; other biliary structures that may be either intraportal (at the portal-parenchymal interface), or extraportal (within the lobule), are called bile ductules. Ductular reaction is used to designate the biliary structures that arise in response to injury.

\section{Statistical Analyses}

Quantitative data are presented as means \pm s.d. Comparisons between pairs were made using Mann-Whitney $U$-test.
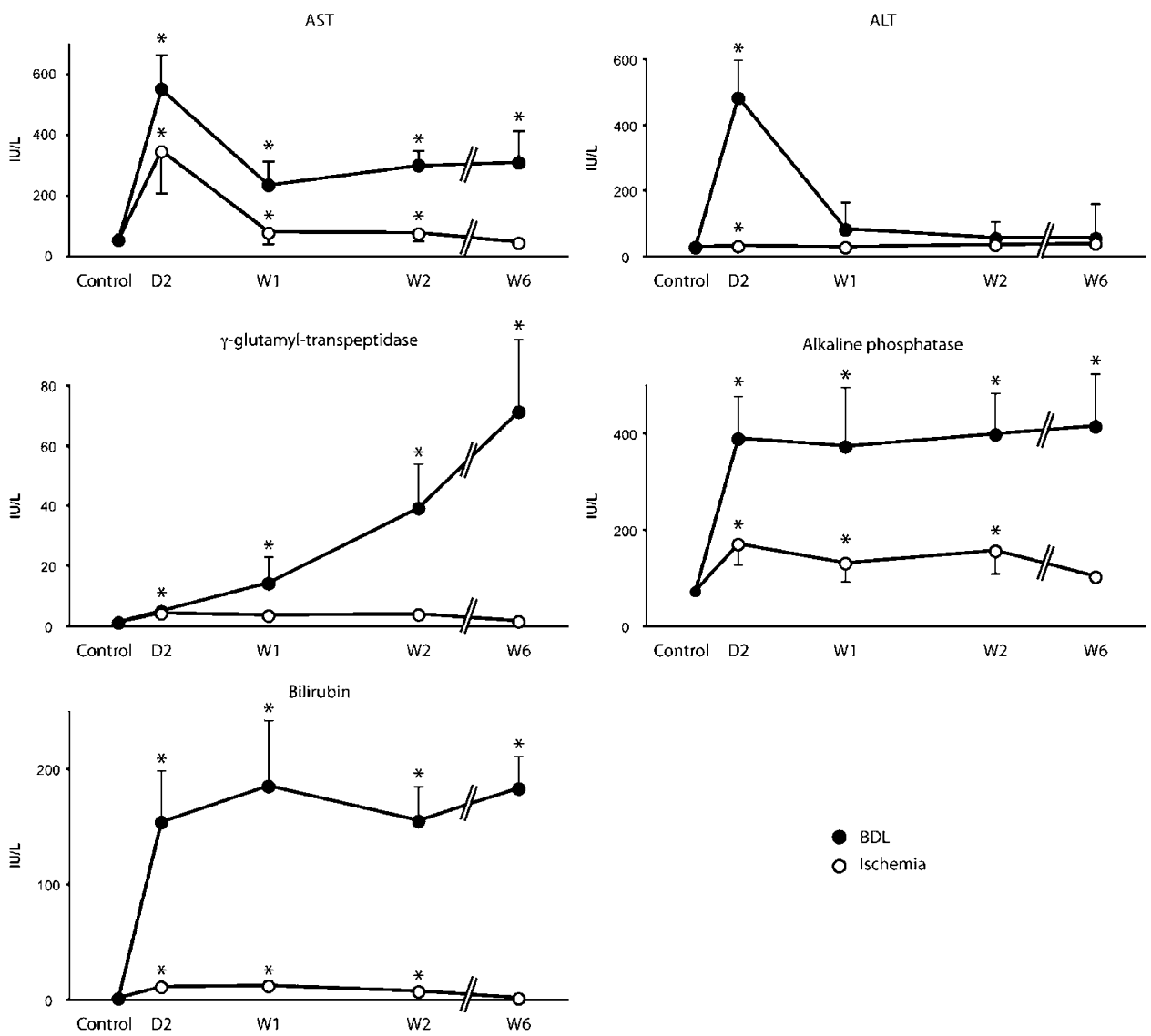

- BDL

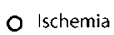

Figure 1 Serum tests of liver injury in arterial liver ischemia and BDL. Serum concentrations of liver enzymes and of total bilirubin were measured in rats with arterial liver ischemia (open circles) or with BDL (closed circles), at different time points after surgery, that is day 2 (D2); weeks 1, 2, 6 (W1, 2, 6). Control values were determined in Sham-operated animals. Results are means \pm s.d. of four animals; ${ }^{\star} P<0.05$ vs control. 
CK19

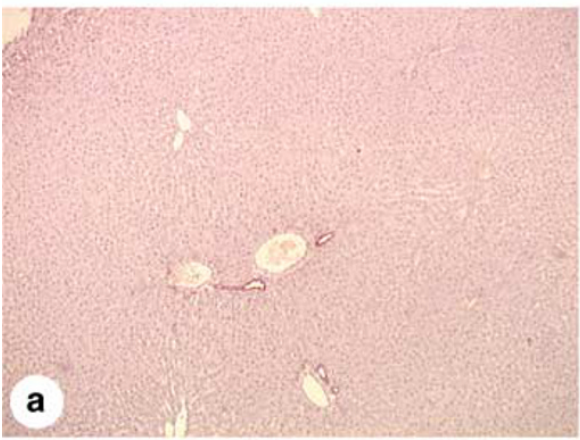

\section{Ischemia}

\section{Day 2}

Sirius Red

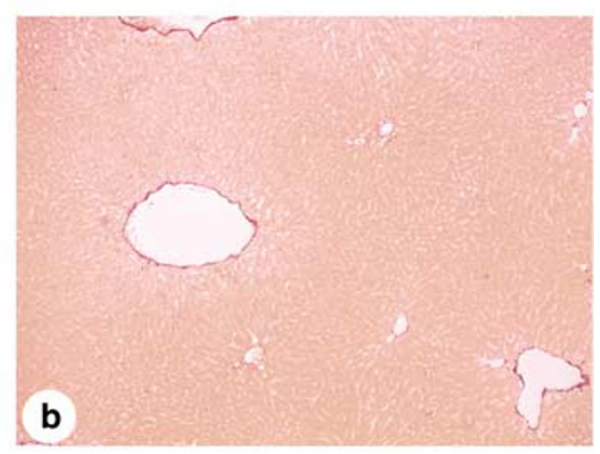

Week 1
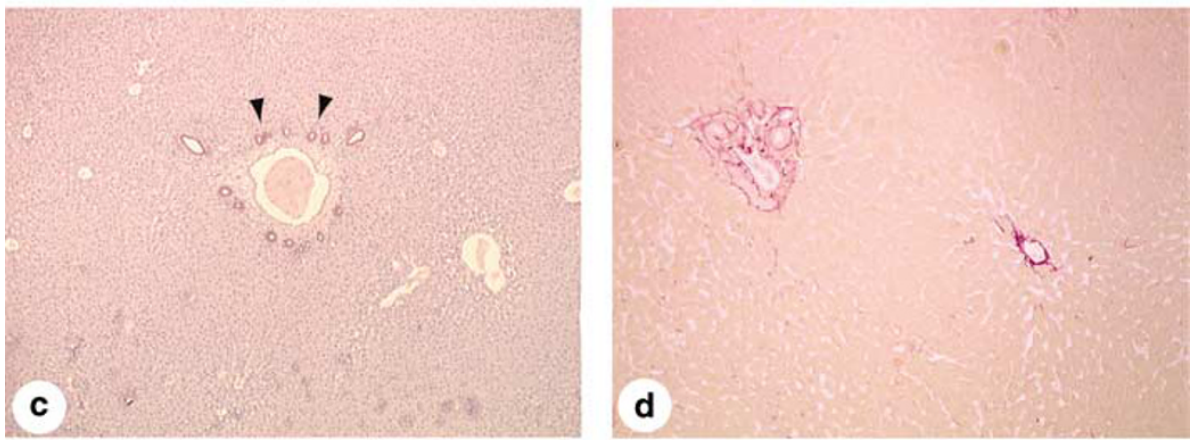

Week 2
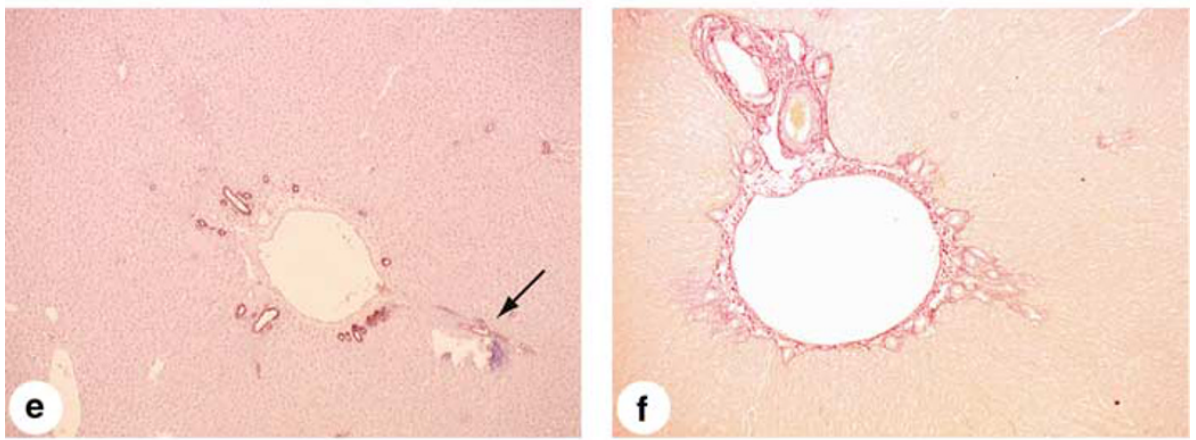

\section{Week 6}
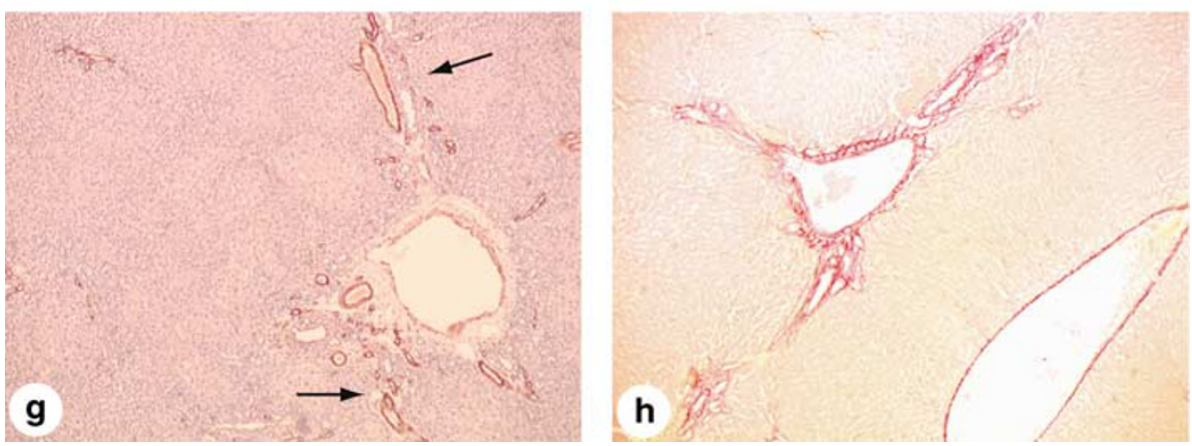

Figure 2 Association between ductular reaction and fibrosis development in ischemia-induced liver injury. Liver tissue sections from rats with arterial liver ischemia, on post-operative day 2 (a, b), weeks 1 (c, d), week $2(\mathbf{e}, \mathbf{f})$ and week $6(\mathbf{g}, \mathbf{h})$, were submitted to CK19 immunolabeling or to Sirius red staining. Portal tract-centered photomicrographs show the emergence of a ductular reaction at the portal tract periphery on week 1 (c, arrowheads), with periportal lobular extensions thereafter (e, g, arrows) and concomitant periductal/ductular accumulation of fibrosis (d, $\mathbf{f}, \mathbf{h}$ ). Results are representative of four animals at each time point; original magnification $\times 100$. 
Correlations were determined using the Spearman rank coefficient. Statistical significance was set at $P<0.05$.

\section{RESULTS \\ Fibrogenic Response in Ischemia- and BDL-Induced Liver Injury}

As the fibrogenic response differs in transient and sustained liver injury, ${ }^{20}$ we chose two models of liver injury, that is arterial liver ischemia and BDL, both of cholestatic type but with distinct evolutions. The results of serum biochemical tests monitored over 6 weeks (Figure 1), attest that rats with arterial liver ischemia developed moderate and transient cholestatic liver injury, whereas those with BDL, developed severe and sustained cholestatic injury. In both models, we analyzed the development of fibrosis and its relationship with the ductular reaction that is typically induced in cholestatic liver injury. In arterial liver ischemia, 2 days after the onset of injury, no ductular reaction nor fibrosis were detected, as shown by CK19 immunolabeling (Figure 2a) and Sirius red staining (Figure 2b), which were similar to controls (not shown). Accordingly, morphometric analyses revealed no significant increase in CK19 immunolabeling or Sirius red staining at that time (Figure 3). A ductular reaction made of well-formed ductular structures located at the periphery of portal tracts with little extension in the periportal area, was detected after 1 week (Figure 2c, arrowheads). After 2 and 6 weeks, lobular extensions were more abundant but remained confined to the periportal areas (Figure $2 \mathrm{e}$ and g, arrows). In

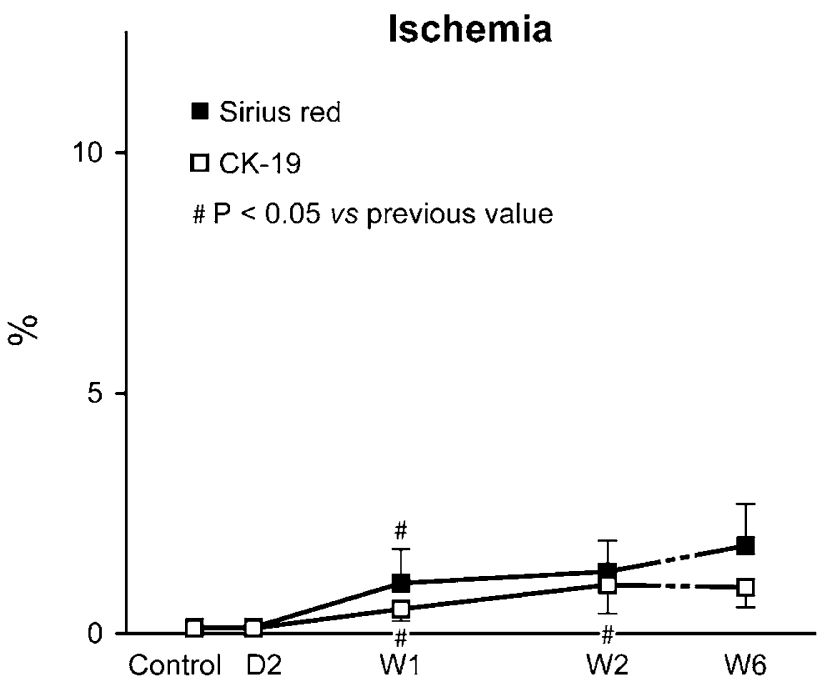

Figure 3 Progression rates of ductular reaction and fibrosis in ischemiainduced liver injury. Liver tissue sections from rats with Sham operation (control), or with arterial liver ischemia at different time points after surgery, that isw day 2 (D2); weeks 1, 2, 6 (W1, 2, 6), were submitted to CK19 immunolabeling or to Sirius red staining, as shown in Figure 2. The CK19labeled (open squares) and Sirius red-stained (closed squares) areas were measured using a computerized image analysis system and expressed as a percentage of total analyzed area. Results are means \pm s.d. from 10 consecutive fields; ${ }^{\#} P<0.05$ vs previous value. this model, fibrosis became detectable by Sirius red staining, 1 week after the onset of injury, and from this time onward, was localized mainly around ductular structures, in the portal and periportal areas (Figure $2 \mathrm{~d}, \mathrm{f}$ and $\mathrm{h}$ ). No complete fibrous septal connection between portal tracts developed up until the end of follow-up at 6 weeks. Morphometric analyses (Figure 3) demonstrated that the progression rates of fibrosis and of ductular reaction were moderate and correlated with each other $\left(r^{2}=0.82 ; P=0.04\right)$. Both of them were stabilized after 2 weeks.

In BDL rats, a ductular reaction was readily detected after 2 days, as shown by CK19 immunoreactivity (Figure 4a). At that time, the reaction was essentially made of well-formed ductular structures located in portal tracts (Figure 4a, arrowheads) but also comprised, although to a lesser extent, poorly formed structures in the periportal area (Figure 4a, arrows). One week after BDL, the ductular reaction extended more deeply in the lobule and started to form porto-portal bridges (Figure 4c). After 2 weeks, the ductular reaction was even more extensive and started to circumscribe nodules of liver parenchyma (Figure 4e, arrowheads). After 6 weeks, the ductular reaction was extremely intense and delineated multiple micronodules in the liver (Figure $4 \mathrm{~g}$ ). Sirius red staining of the same samples showed that fibrosis developed in close association with the ductular reaction. As soon as after 2 days and subsequently, fibrosis was detected mainly as periductular deposits (Figure $4 \mathrm{~b}, \mathrm{~d}, \mathrm{f}$ and h). After 6 weeks (Figure $4 \mathrm{~h}$ ), in addition to a massive periductular pattern (arrowheads), fibrosis formed fine lobular septa (arrows), and overall defined micronodular cirrhosis. Morphometric analyses of CK19 labeling and Sirius red staining confirmed a constant and marked progression both of the ductular reaction and of liver fibrosis, up to 6 weeks (Figure 5). They demonstrated a significant correlation between the progression rates of fibrosis and of ductular reaction $\left(r^{2}=0.941\right.$; $P=0.02$ ), in this model also. In summary, arterial liver ischemia provides a model of slow progression and early stabilization of fibrosis, which after 6 weeks, does not exceed F2, in the METAVIR scoring system. ${ }^{30}$ By contrast, BDL represents a model of liver fibrosis of rapid progression, which leads to cirrhosis (F4, in the METAVIR scoring system) within 6 weeks. In both models, biliary-type liver fibrosis develops close to the ductular reaction, and the progression rates of fibrosis and of the ductular reaction significantly correlate with each other.

\section{Response of HSCs and of Portal Mesenchymal Cells to Ischemia- and BDL-Induced Liver Injury}

Next experiments were aimed to determine the response of HSCs and other, for example portal, mesenchymal cells to the two types of ischemia- and BDL-induced liver injury, based on the following postulate: in the course of myofibroblastic differentiation, rat HSCs overexpress desmin before $\alpha$-SMA and have a limited proliferative capacity, whereas myofibroblasts derived from portal mesenchymal liver cells are highly 


\section{CK19}

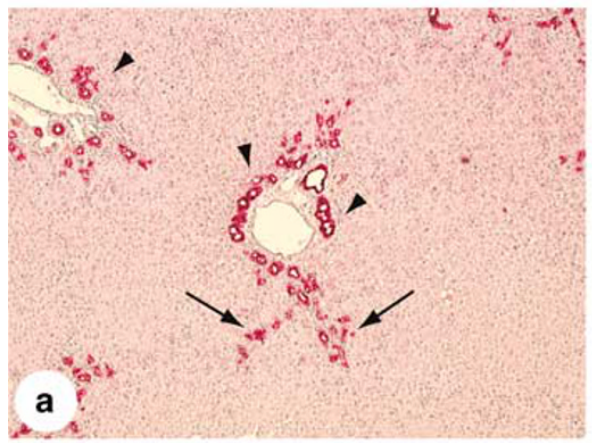

Day 2

Sirius Red

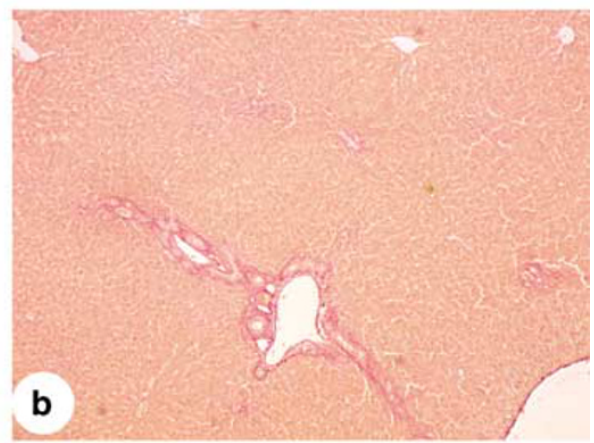

Week 1
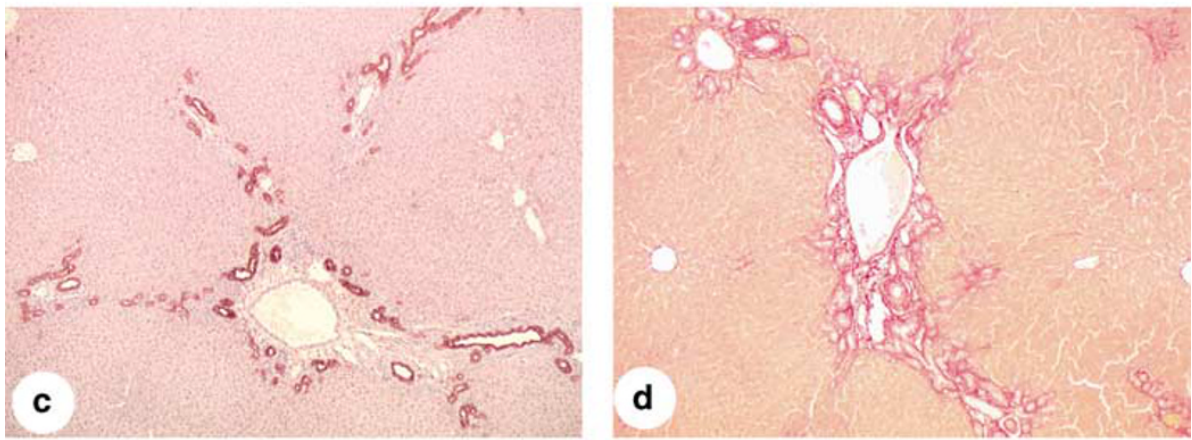

Week 2
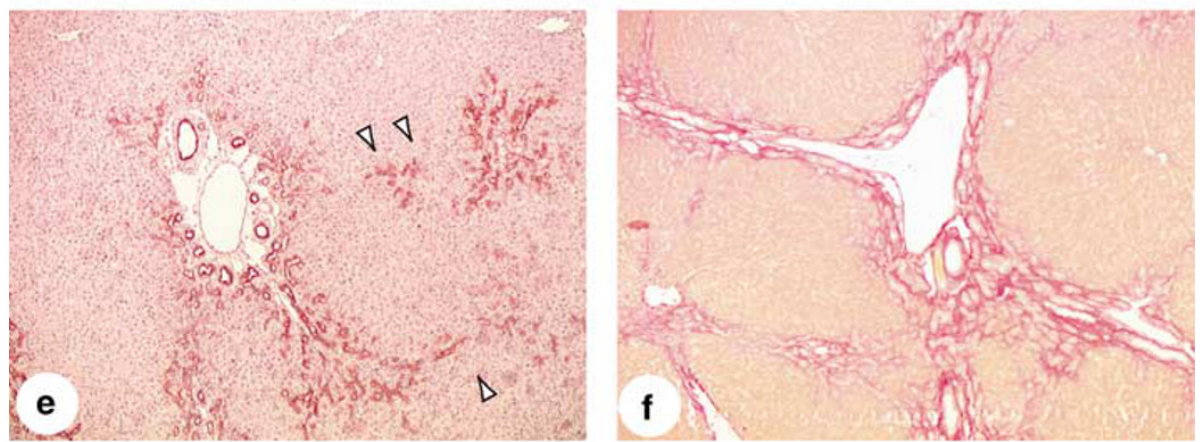

\section{Week 6}
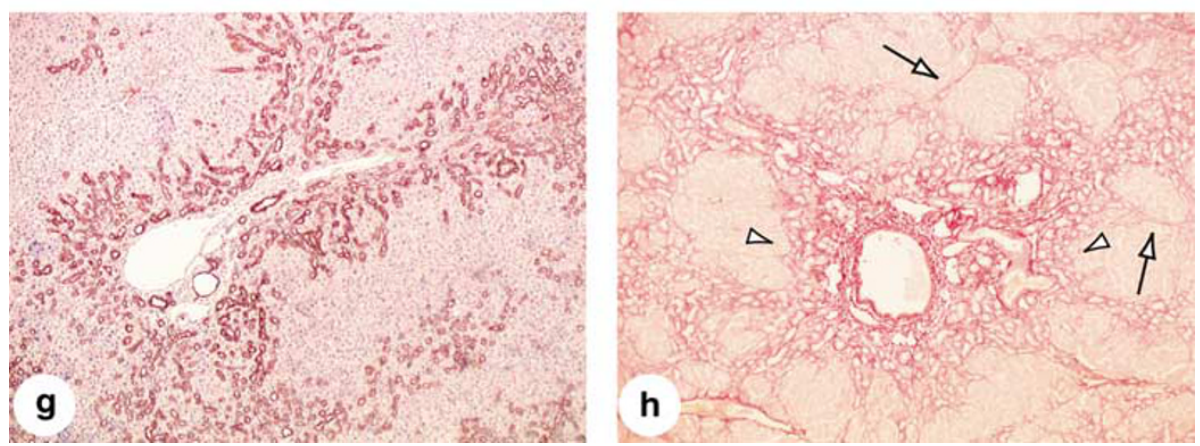

Figure 4 Association between ductular reaction and fibrosis development in BDLinduced liver injury. Liver tissue sections from rats with $\mathrm{BDL}$, on post-operative day $2(\mathbf{a}, \mathbf{b})$ week 1 (c, d), week $2(\mathbf{e}, \mathbf{f})$ and week $6(\mathbf{g}, \mathbf{h})$, were submitted to CK19 immunolabeling or to Sirius red staining. Ductular reaction initially arose in portal tracts (a, arrowheads) with limited periportal lobular extensions (a, arrows), and subsequently formed portoportal bridges (c) that ultimately circumscribed nodules of liver parenchyma (e, arrowheads, g). Fibrosis developed around bile duct and ductular structures (b, d, f, h) leading after 6 weeks to cirrhotic nodules delineated by periductular fibrosis (h, arrowheads) and fine lobular septa (h, arrows). Results are representative of four animals at each time point; original magnification $\times 100$. 


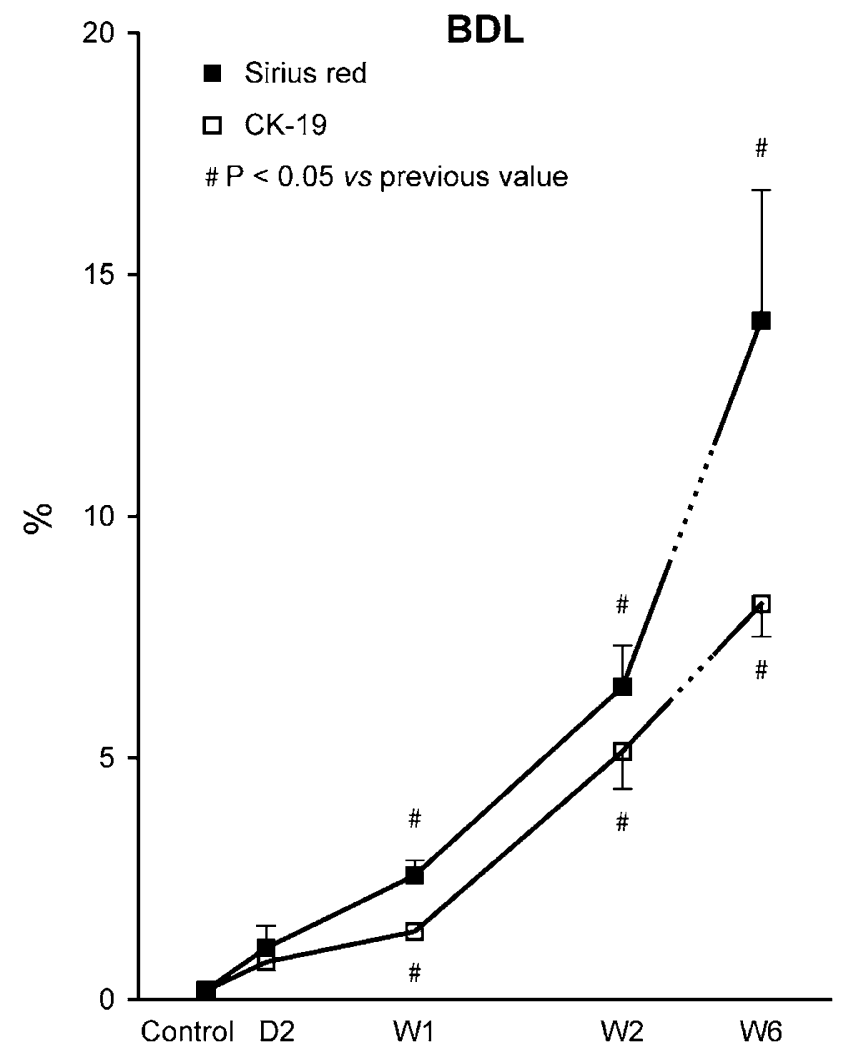

Figure 5 Progression rates of ductular reaction and fibrosis in BDL-induced liver injury. Liver tissue sections from rats with Sham operation (control), or with $\mathrm{BDL}$ at different time points after surgery, that is day 2 (D2); weeks 1, 2, 6 (W1, 2, 6), were submitted to CK19 immunolabeling or to Sirius red staining, as shown in Figure 4. The CK19-labeled (open squares) and Sirius red-stained (closed squares) areas were measured using a computerized image analysis system and expressed as a percentage of total analyzed area. Results are means \pm s.d. from 10 consecutive fields; ${ }^{\#} P<0.05$ vs previous value.

proliferative and progressively lose desmin; as a result of both their proliferative and immunophenotypic evolutive profiles, all fully converted myofibroblastic rat HSCs express desmin in addition to $\alpha$-SMA, whereas only a small subset of the myofibroblastic population derived from portal mesenchymal liver cells ultimately express desmin. ${ }^{16,21}$ Here, we followed $\alpha$-SMA and desmin immunoreactivities over time in the two models of liver injury, by quantitative analyses, and semi-quantitative analyses of their distribution among the compartments defined as lobular, portal/septal, and at the portal/septal-lobular interface. In normal control rats, $\alpha$ SMA and desmin immunoreactivities were restricted to the wall of portal veins, hepatic arterioles and terminal hepatic venules. In addition, occasional desmin immunoreactive HSCs were observed within the lobule (data not shown). Low levels of desmin expression in periportal HSCs in normal rat liver was reported previously in different conditions of tissue fixation/embedment. ${ }^{25}$

In rats with arterial liver ischemia, an accumulation of $\alpha$-SMA-immunoreactive cells was detected around native bile ducts as soon as 2 days after the onset of ischemia (Figure 6a, arrowheads). Morphometric analyses confirmed that a significant increase in $\alpha$-SMA immunoreactivity occurred before any significant increase in CK19 or Sirius red stainings (Figures 3 and 7). Desmin expression, while very rare in these periductal myofibroblasts, was induced in a large number of HSCs with typical cytoplasmic processes within the lobule (Figure 6b, arrows), which accounted for a significant increase in desmin immunoreactivity at this stage (Figure 7, Table 1). After 1 week, numerous $\alpha$-SMA-immunoreactive cells were detected around bile duct and ductular structures (Figure 6c, arrowheads). At this time, only some of the periductular cells located at the interface with the lobule also expressed desmin (Figure 6d, arrowheads), while in the lobule, the number of desmin-positive HSCs (Figure 6d, arrows; $\mathrm{d}^{\prime}$ ), was further increased compared to day 2 (Figure 7 , Table 1). At later time points, $\alpha$-SMA-immunoreactivity returned to control levels (Figure 7), and after 6 weeks was detected predominantly in vascular walls including those of newly formed blood vessels detected in portal tracts (Figure 6 , arrows). At the end of follow-up, desmin expression was also reduced but remained significantly higher compared to control (Figure 7). Residual expression was found in HSCs and in the intraportal neo-formed vessels (Figure 6f, arrows (Figure $6 \mathrm{f}^{\prime}$, Table 1). In BDL rats, 2 days after the induction of injury, $\alpha$-SMA immunoreactive cells that colocalized with fibrosis, were detected around bile duct and ductular structures (Figure 8a, arrowheads). Some of these cells, located at the interface with the lobule, were desminpositive, (Figure $8 \mathrm{~b}$, arrowhead), while the remaining majority was desmin-negative. Simultaneously, desmin immunoreactivity was also detected in sinusoidal cells, with a predominant localization in the periportal area, close to the interface with bile ductules (Figure 8b, arrows; Table 2). At later time points, ie 1 week (Figure 8c) and 2 weeks (not shown) after BDL, the ductular structures were more completely encircled by $\alpha$-SMA-immunoreactive cells. At these stages, the vast majority of peribiliary myofibroblasts were desmin-negative, with the exception of few cells facing the lobule (Figure 8d, arrowheads), while the amount of desmin-positive HSCs within sinusoids (Figure $8 \mathrm{~d}$ and $\mathrm{d}^{\prime}$, arrows) was even higher than after 2 days (Table 2). In keeping with on-going progression of the ductular reaction and fibrosis, $\alpha$-SMA immunoreactivity further increased between 2 and 6 weeks (Figure 9). After 6 weeks, at the stage of cirrhosis, $\alpha$-SMA-immunoreactive cells were mainly concentrated in large septa connected to portal tracts (Figure 8e and $\mathrm{e}^{\prime}$, arrowheads). However, at this stage, $\alpha$-SMA immunoreactivity was also detected in isolated cells within sinusoids (Figure 8e, arrows) and around small ductules deeply located in the lobule (Figure $8 \mathrm{e}^{\prime}$ ). At this stage, desmin immunoreactivity had become less abundant (Figure 9) and was detected mainly within sinusoids (Figure $8 \mathrm{~h}$, arrows) and in a few periductular cells (Figure 8h, arrowheads; Table 2). 


\section{$\alpha-$ SMA}

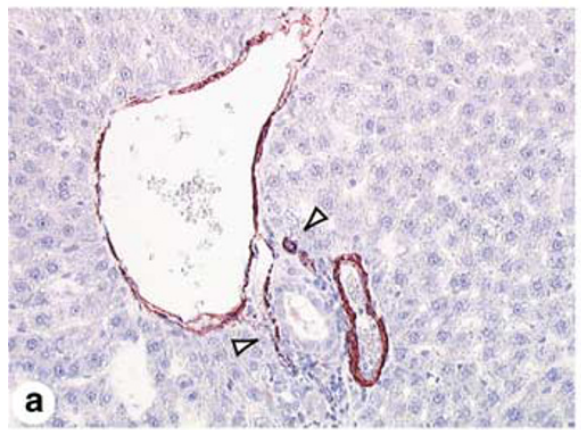

\section{Ischemia}

Day 2

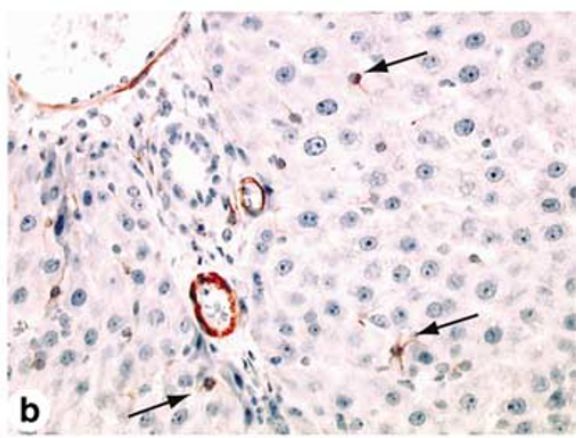

\section{Week 1}
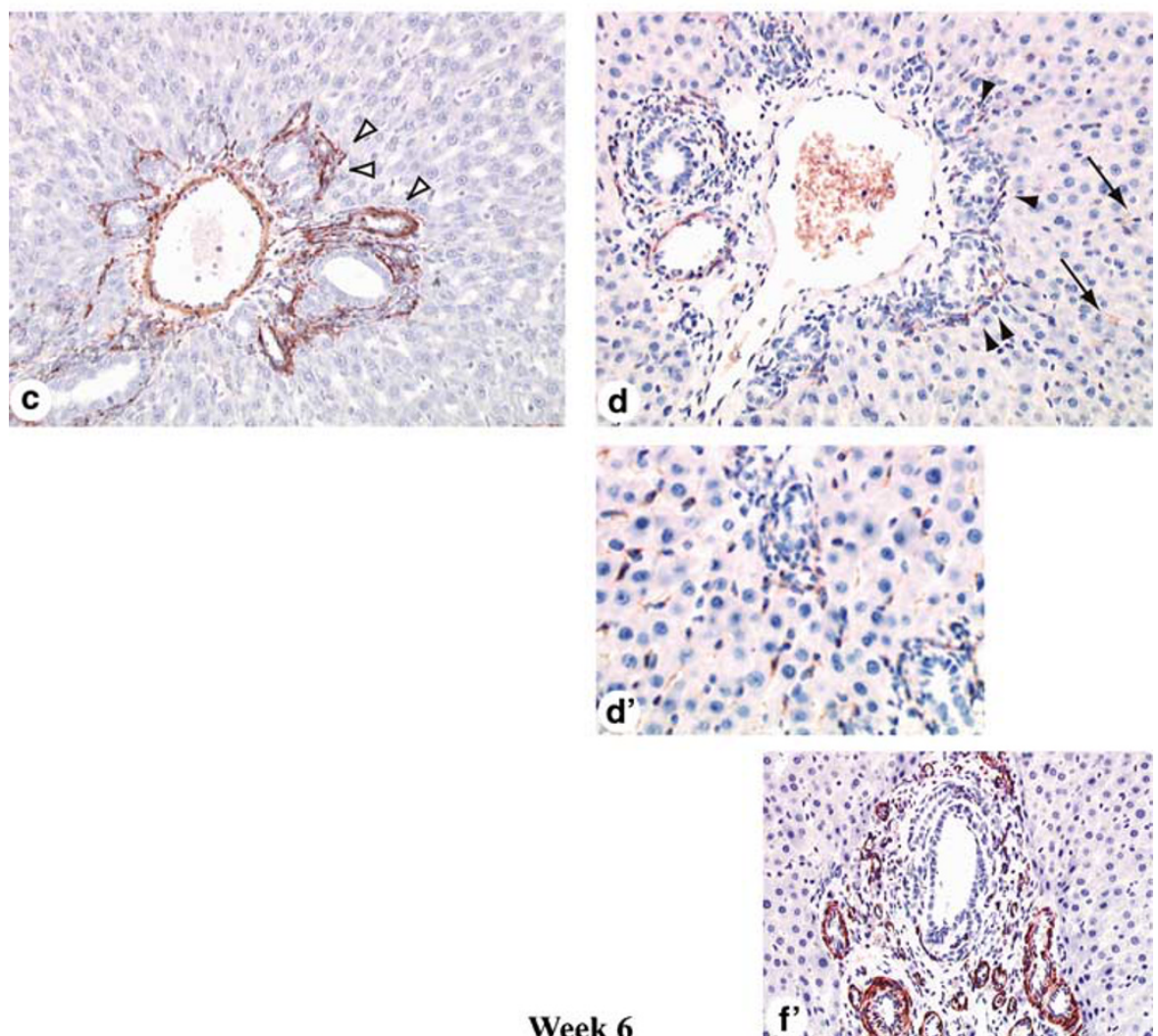

Week 6

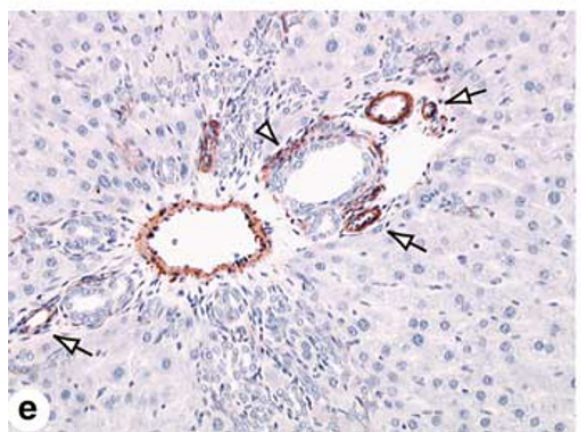

Figure 6 Expressions of $\alpha$-SMA and desmin in ischemia-induced injury. Liver tissue sections from rats with arterial liver ischemia, on postoperative day 2 (a, b), week 1 (c, d, d'), week 2 (not shown) and week $6(\mathbf{e}, \mathbf{f})$, were submitted to $\alpha$-SMA $(\mathbf{a}, \mathbf{c}, \mathbf{e})$ or desmin $\left(\mathbf{b}, \mathbf{d}, \mathbf{d}^{\prime}, \mathbf{f}\right)$ immunolabeling. Besides normal $\alpha$-SMA and desmin expressions in vessel walls, $\alpha$-SMA was detected at initial stages in cells that surrounded bile duct and ductular structures (a, c, arrowheads) and at the end of follow-up mostly in newly formed vessels within portal tracts (e, arrows), in addition to residual expression in periductal/ductular cells (e, arrowhead). Desmin was detected at initial stages in stellate-shaped sinusoidal cells (b, d, arrows; $\mathbf{d}^{\prime}$ ), and in some periductal/ductular cells mainly located at the lobule interface (d, arrowheads; $\mathbf{d}^{\prime}$ ) and at the end of follow-up in newly formed portal vessels (f, arrows; $f^{\prime}$ ), in addition to residual expression in sinusoidal cells. Results are representative of four animals at each time point; original magnification $\times 200\left(\mathbf{a}, \mathbf{c}-\mathbf{f}, \mathbf{f}^{\prime}\right), \times 400\left(\mathbf{b}, \mathbf{d}^{\prime}\right)$. 


\section{DISCUSSION}

In this study, we investigated the liver wound healing response to cholestatic liver injury, in two models that differ not only by the mechanism, but also by the severity and outcome of liver injury. In arterial liver ischemia as opposed to $\mathrm{BDL}$, obstruction is not the major cause of cholestasis, and cholestatic injury is much less intense as indicated by lower values of liver enzymes. Furthermore, in this model, cholestatic injury is spontaneously resolutive within 6 weeks. Accordingly, the severity and progression rate of fibrosis were markedly lower in arterial liver ischemia than in BDL. After 6 weeks, fibrosis was stabilized and did not exceed F2 in arterial liver ischemia, whereas at that time in the BDL model, cirrhosis (F4) was established. Despite these major differences, we found that in both models, and in agreement with previous observations in BDL, ${ }^{7,31,32}$ HSCs underwent early phenotypic changes marked by desmin overexpression. As arterial liver ischemia provides a model of liver fibrosis of slow progression, it is noteworthy that desmin overexpression in HSCs was particularly intense in this model.

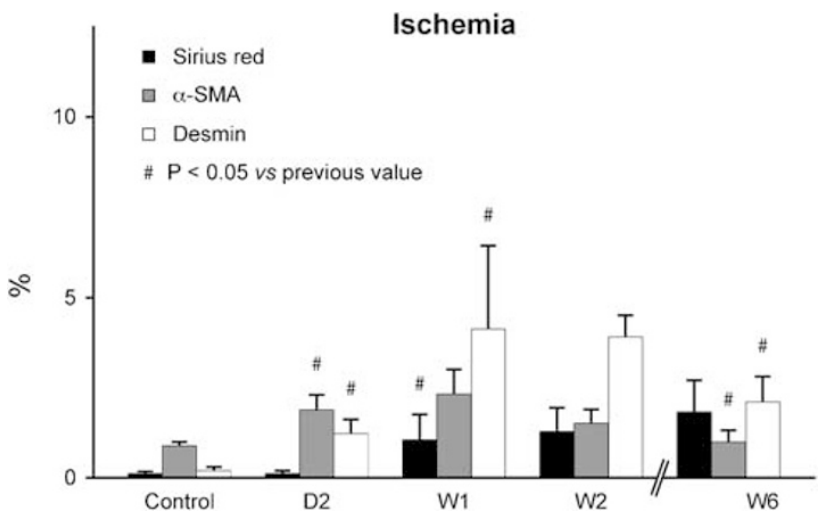

Figure $7 \alpha$-SMA and desmin expression profiles according to fibrosis evolution in ischemia-induced injury. Liver tissue sections from rats with Sham operation (control), or with arterial liver ischemia at different time points after surgery, that is day 2 (D2); weeks 1, 2, 6 (W1, 2, 6), were submitted to $\alpha$-SMA or desmin immunolabeling, as shown in Figure 6 . The $\alpha$-SMA-labeled (grey bars) and desmin-labeled (white bars) areas were measured using a computerized image analysis system. The results, expressed as a percentage of total analyzed area, are shown in comparison with Sirius red-stained areas (black bars) and represent the means \pm s.d. of four animals; ${ }^{\#} P<0.05$ vs previous value.
We may conclude from this finding that in cholestatic injury, as previously reported in acute $\mathrm{CCl}_{4}$-induced cytolytic injury, ${ }^{20,24,25}$ phenotypic changes in HSCs, such as desmin overexpression or DNA synthesis, do not correlate with fibrosis progression thereafter. To a large extent, these phenotypic changes caused by acute injury are reversible, as indicated here by the demonstration that in the same model, desmin overexpression in HSCs was significantly reduced at the end of follow-up. One may postulate that this response of HSCs has beneficial effects on the repair of wounded hepatocytes, a possibility supported by previous studies ${ }^{20,33-36}$ and here by the fact that all signs of liver injury had disappeared at the end of follow-up in the model of arterial liver ischemia. In both models, the accumulation of fibrosis coincided with that of $\alpha$-SMA-labeled myofibroblasts, confirming that the vast majority of liver fibrogenic cells are $\alpha$ SMA positive. At early time points, combined expression of $\alpha$-SMA and desmin was found at the interface of portal/septal ductules with the lobule. As it was previously shown by electron microscopy that at this time in BDL rats, fat dropletcontaining HSCs that were disconnected from the liver lobule (thus called denuded HSCs), congregated in the front of biliary fibrosis at the periportal fibrous tissue-lobular interface, ${ }^{37}$ we may postulate that these cells comprised at least in part myofibroblastic HSCs. Nevertheless, time course analyses showed that the vast majority of $\alpha$-SMA-labeled cells that co-localized with fibrosis became desmin-negative over time, suggesting that they derived mainly from portal mesenchymal cells distinct from HSCs, except for intralobular myofibroblastic HSCs detected in BDL cirrhotic liver. The prominent accumulation of portal myofibroblasts over myofibrolastic HSCs, at least in biliary fibrosis, is in keeping with comparative studies of the two cell types in culture, showing that portal myofibroblasts are much more proliferative, whereas myofibrolastic HSCs are more susceptible to spontaneous and provoked apoptosis. ${ }^{38,39}$ In the model of arterial liver ischemia, the regression of injury was accompanied by a stabilization of fibrosis and a regression of $\alpha$-SMA-immunoreactive cells, which were undetectable after 6 weeks, except for the cells lining newly formed vessels. As we previously showed that VEGF expression was induced both in cholangiocytes and in periportal hepatocytes in the model of arterial liver ischemia, we may anticipate that

Table 1 Distribution of $\alpha$-actin and desmin-immunoreactive cells in ischemia-induced liver injury

\begin{tabular}{|c|c|c|c|c|c|c|c|c|}
\hline & \multicolumn{2}{|c|}{ Day 2} & \multicolumn{2}{|c|}{ Week 1} & \multicolumn{2}{|c|}{ Week 2} & \multicolumn{2}{|c|}{ Week 6} \\
\hline & $\alpha$-SMA & Desmin & $\alpha$-SMA & Desmin & $\alpha$-SMA & Desmin & $\alpha$-SMA & Desmin \\
\hline Portal/septal & + & - & ++ & - & + & - & + & - \\
\hline Interface & + & - & ++ & + & + & - & + & - \\
\hline Lobular & - & ++ & - & +++ & - & ++ & - & + \\
\hline
\end{tabular}




\section{$\alpha$-SMA}

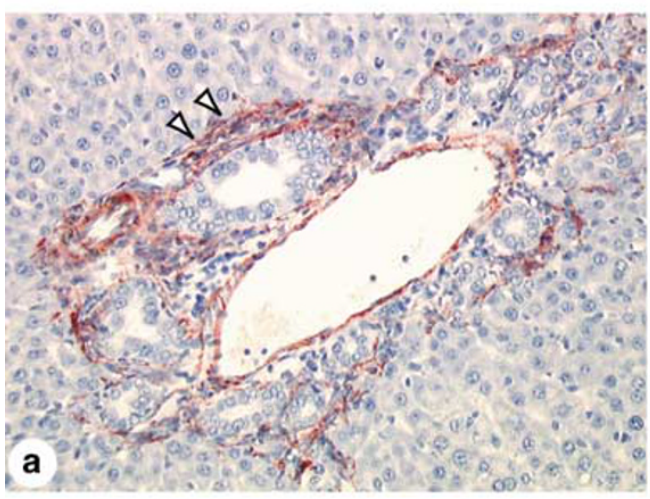

BDL

\section{Day 2}

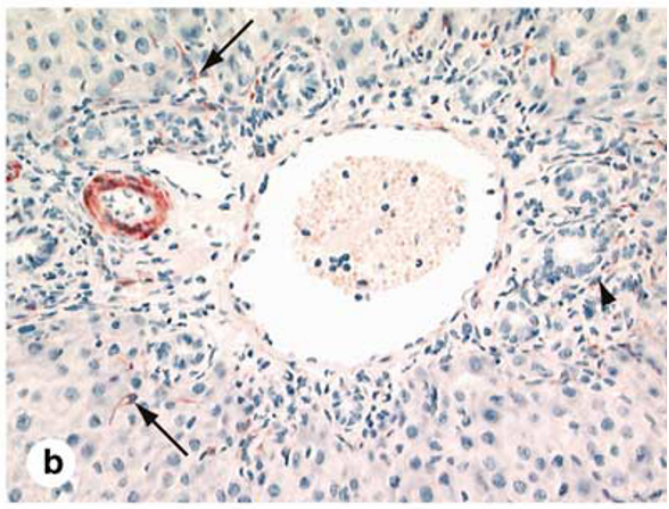

\section{Week 1}
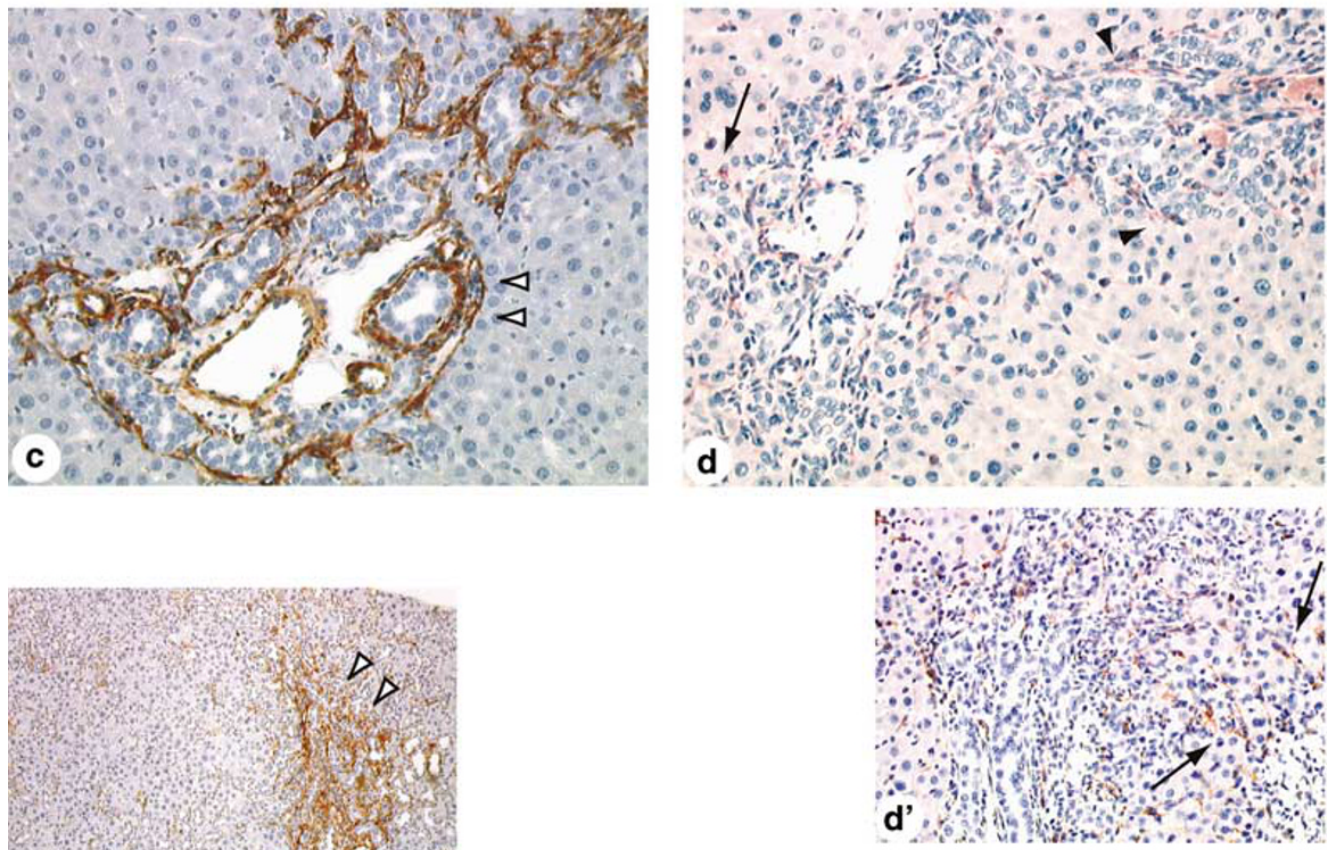

\section{Week 6}
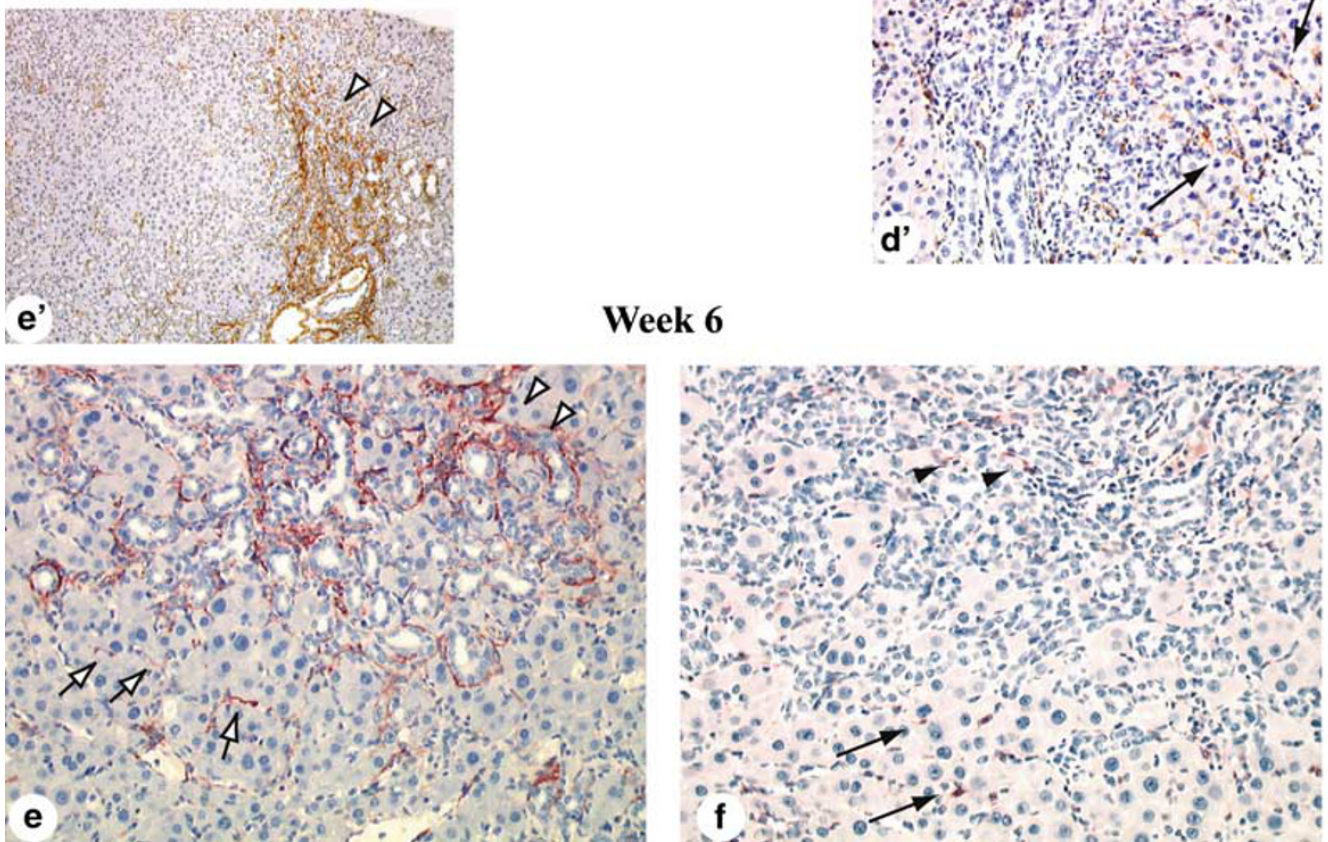

\section{Desmin}

Figure 8 Expressions of $\alpha$-SMA and desmin in BDL-induced injury. Liver tissue sections from rats with $B D L$, on post-operative day $2(\mathbf{a}, \mathbf{b})$, week 1 (c, d, d'), week 2 (not shown) and week $6\left(\mathbf{e}, \mathbf{e}^{\prime}, \mathbf{f}\right)$, were submitted to $\alpha$-SMA $\left(\mathbf{a}, \mathbf{c}, \mathbf{e}, \mathbf{e}^{\prime}\right)$ or desmin $\left(\mathbf{b}, \mathbf{d}, \mathbf{d}^{\prime}\right.$, f) immunolabeling. Besides normal $\alpha$-SMA and desmin expressions in vessel walls, $\alpha$-SMA was detected at all stages in cells that surrounded bile duct structures $\left(\mathbf{a}, \mathbf{c}, \mathbf{e}, \mathbf{e}^{\prime}\right.$, arrowheads) and at the stage of cirrhosis also in sinusoidal cells (e, arrows). Desmin was detected at initial stages, in sinusoidal cells (b, $\mathbf{d}$, $\mathbf{d}^{\prime}$, arrows), and in some periductular cells almost restricted to the lobule interface $(\mathbf{b}, \mathbf{d}$, arrowheads; $\mathbf{d}^{\prime}$ ) while at the stage of cirrhosis, residual expression was found mostly in sinusoidal cells (f, arrows), and in rare periductular cells (f, arrowheads). Results are representative of four animals at each time point; original magnification $\times 200\left(\mathbf{a}-\mathbf{d}, \mathbf{d}^{\prime}, \mathbf{e}\right.$, f), $100\left(\mathbf{e}^{\prime}\right)$. 
Table 2 Distribution of $\alpha$-actin and desmin-immunoreactive cells in BDL-induced liver injury

\begin{tabular}{|c|c|c|c|c|c|c|c|c|}
\hline & \multicolumn{2}{|c|}{ Day 2} & \multicolumn{2}{|c|}{ Week 1} & \multicolumn{2}{|c|}{ Week 2} & \multicolumn{2}{|c|}{ Week 6} \\
\hline & $\alpha-S M A$ & Desmin & $\alpha$-SMA & Desmin & $\alpha$-SMA & Desmin & $\alpha-S M A$ & Desmin \\
\hline Portal/septal & + & - & ++ & + & ++ & + & +++ & + \\
\hline Interface & ++ & + & +++ & + & +++ & + & +++ & - \\
\hline Lobular & - & + & - & ++ & - & ++ & + & + \\
\hline
\end{tabular}

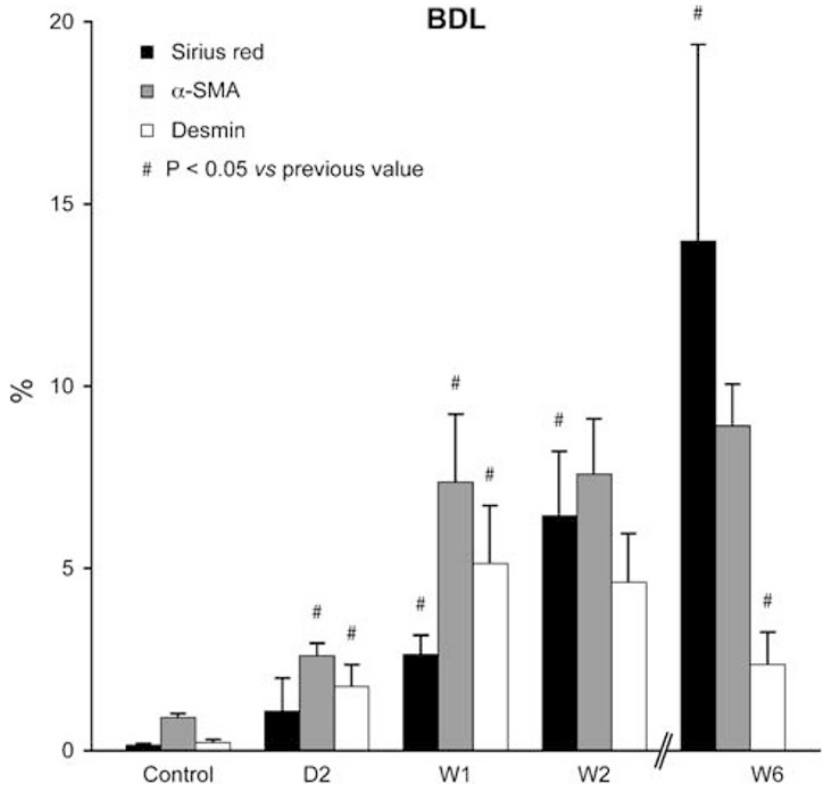

Figure $9 \alpha$-SMA and desmin expression profiles according to fibrosis evolution in BDL-induced injury. Liver tissue sections from rats with Sham operation (control), or with $\mathrm{BDL}$ at different time points after surgery, that is day 2 (D2); weeks $1,2,6(\mathrm{~W} 1,2,6)$, were submitted to $\alpha$-SMA or desmin immunolabeling, as shown in Figure 8. The $\alpha$-SMA-labeled (grey bars) and desmin-labeled (white bars) areas were measured using a computerized image analysis system. The results, expressed as a percentage of the total screened area, are shown in comparison with Sirius red-stained areas (black bars) and represent the means \pm s.d. of four animals; ${ }^{\#} P<0.05$ vs previous value.

VEGF-triggered angiogenesis contributed together with the ductular reaction, to a favorable outcome in this model. ${ }^{26}$ The loss of $\alpha$-SMA-positive cells in residual fibrotic septa is consistent with previous demonstrations that after cessation of $\mathrm{CCL}_{4}$ intoxication in rats, residual septa are characterized by relative hypocellularity and matrix cross-linking, ${ }^{40}$ and that in humans with chronic hepatitis C, $\alpha$-SMA and fibrosis correlate positively at early stage, but negatively at advanced stage. $^{41}$

A strong correlation between fibrosis and ductular reaction, evident in the present study, has been recently reported in patients with chronic hepatitis C. ${ }^{19}$ A relationship between ductular proliferation and fibrosis has also been previously reported in primary biliary cirrhosis. ${ }^{42}$ Different potential mechanism(s) whereby cholangiocytes may promote fibrogenesis have been envisioned. Cholangiocytes may stimulate portal fibrogenic cells and to a certain extent HSCs, through the release of pro-mitogenic, pro-fibrogenic, chemotactic or anti-apoptotic factors. ${ }^{43}$ For example, we previously showed that the Platelet-derived growth factor secreted by cholangiocytes of the ductular reaction was able to induce the chemo-attraction of myofibroblastic HSCs. ${ }^{44}$ It has been shown these cells also secreted the Growth arrest specific gene protein 6 (Gas6), ${ }^{45}$ which is able to protect myofibroblasts from apoptosis, ${ }^{46}$ while the inactivation of Gas6 gene prevents the accumulation of myofibroblats in liver injury. ${ }^{47}$ Conversely, it has been proposed that peribiliary myofibroblasts could regulate cholangiocyte proliferation via their expression of ecto-nucleoside triphosphate diphosphohydrolase. ${ }^{48}$ Finally, cholangiocytes may directly act on matrix accumulation, for example through the release of Tissue Inhibitor Metalloprotease $1 .^{49}$

We conclude that in two models of self-limited and perpetuated liver injury, both of cholestatic type, fibrosis correlates with ductular reaction and is produced by periductal/ ductular myofibroblasts the vast majority of which are desmin negative, suggesting that they derive from portal and periportal mesenchymal cells. Despite a major expansion of desmin-positive HSCs that occurs soon after the onset of injury in both models, only a minority of these cells undergo complete transformation into $\alpha$-SMA positive myofibroblasts and contribute to fibrogenesis. However, these myofibroblastic HSCs may have specific remodeling functions, that is to isolate wounded hepatocytes from the biliary front or to dissect micronodules of hepatocytes at the stage of cirrhosis, after prolonged injury.

1. Hautekeete $M$, Geerts $A$. The hepatic stellate (Ito) cell: its role in human liver disease. Virchows Arch 1997;430:195-207.

2. Friedman S. Molecular regulation of hepatic fibrosis, an integrated cellular response to tissue injury. J Biol Chem 2000;275:2247-2250.

3. De Leeuw A, Mccarthy S, Geerts A, et al. Purified rat liver fat-storing cells in culture divide and contain collagen. Hepatology 1984;4: 392-403.

4. Friedman S, Roll F, Boyles J, et al. Hepatic lipocytes: the principal collagen-producing cells of normal rat liver. Proc Natl Acad Sci 1985;82:8681-8685. 
5. Geerts A, Vrijsen R, Rauterberg J, et al. In vitro differenciation of fatstoring cells parallels marked increase of collagen synthesis and secretion. J Hepatol 1989;9:59-68.

6. Maher J, Mcguire R. Extracellular matrix gene expression increases preferentially in rat lipocytes and sinusoidal endothelial cells during hepatic fibrosis in vivo. J Clin Invest 1990;86:1641-1648.

7. Kinnman N, Goria D, Wendum D, et al. Hepatic stellate proliferation is an early platelet-derived growth factor mediated cellular event in rat cholestatic liver injury. Lab Invest 2001;81:1709-1716.

8. Kent $\mathrm{G}$, Gay $\mathrm{S}$, Inouye $\mathrm{T}$, et al. Vitamin A-containing lipocytes and formation of type III collagen in liver injury. Proc Natl Acad Sci 1976:73:3719-3722.

9. Mak K, Lieber C. Lipocytes and transitional cells in alcoholic liver disease: a morphometric study. Hepatology 1988;8:1027-1033.

10. Schmitt-Graff A, Chakroun G, Gabbiani G. Modulation of perisinusoidal cell cytoskeletal features during experimental hepatic fibrosis. Virchows Arch 1993;422:99-107.

11. Guyot C, Lepreux S, Combe $C$, et al. Hepatic fibrosis and cirrhosis: the (myo)fibroblastic cell subpopulations involved. Int J Biochem Cell Biol 2006;38:135-151.

12. Tang L, Tanaka $Y$, Marumo F, et al. Phenotypic change in portal fibroblasts in biliary fibrosis. Liver 1994;14:76-82.

13. Tuchweber $B$, Desmoulière $A$, Bochaton-Piallat $M-L$, et al. Proliferation and phenotypic modulation of portal fibroblasts in early stages of cholestatic fibrosis in the rat. Lab Invest 1996;74:265-278.

14. Uchio K, Tuchweber B, Manabe $\mathrm{N}$, et al. Cellular retinol-binding protein-1 expression and modulation during in vivo and in vitro myofibroblastic differenciation of rat hepatic stellate cells and portal fibroblasts. Lab Invest 2002;82:619-628.

15. Dranoff J, Kruglov E, Robson S, et al. The ecto-nucleoside triphosphate diphosphohydrolase NTPDase2/CD39L1 is expressed in a novel functional compartment within the liver. Hepatology 2002;36: $1135-1144$.

16. Kinnman N, Francoz C, Barbu V, et al. The myofibroblastic conversion of peribiliary fibrogenic cells distinct from hepatic stellate cells is stimulated by platelet-derived gfowth factor during liver fibrogenesis. Lab Invest 2003;83:163-173.

17. Ramadori G, Saile B. Portal tract fibrogenesis in the liver. Lab Invest 2004;84:153-159.

18. Michalak S, Rousselet M, Bedossa P, et al. Respective roles of portoseptal fibrosis and centrilobular fibrosis in alcoholic liver disease. J Pathol 2003;201:55-62.

19. Clouston A, Powell E, Walsh $M$, et al. Fibrosis correlates with a ductular reaction in hepatitis $C$ : roles of impaired replication, progenitor cells and steatosis. Hepatology 2005;41:809-818.

20. Knittel T, Kobold D, Piscaglia F, et al. Localization of liver myofibroblasts and hepatic stellate cells in normal and diseased rat livers: distinct roles of (myo-)fibroblast subpopulations in hepatic tissue repair. Histochem Cell Biol 1999;112:387-401.

21. Knittel T, Kobold D, Saile B, et al. Rat liver myofibroblasts and hepatic stellate cells: different cell population of the fibroblast lineage with fibrogenic potential. Gastroenterology 1999;117:1205-1221.

22. Cassiman D, Libbrecht $L$, Desmet V, et al. Hepatic stellate cell/ myofibroblast subpopulations in fibrotic human and rat livers. J Hepatol 2002;36:200-209.

23. Nakatani K, Tanaka H, lkeda K, et al. Expression of NCAM in activated portal fibroblasts during regeneration of the rat liver after partial hepatectomy. Arch Histol Cytol 2006;69:61-72.

24. Burt A, Robertson J, Heir J, et al. Desmin-containing stellate cells in rat liver: distribution in normal animals and response to experimental liver injury. J Pathol 1986;150:29-35.

25. Geerts A, Lazou J, De Bleser $P$, et al. Tissue distribution quantitation and proliferation kinetic of fat-storing cells in carbon tetrachlorideinjured rat liver. Hepatology 1991;13:1193-1202.

26. Beaussier $M$, Wendum $D$, Fouassier $L$, et al. Adaptative bile duct proliferative response in experimental bile duct ischemia. J Hepatol 2005;42:257-265.

27. Kountouras J, Billing B, Scheuer P. Prolonged bile duct obstruction: a new experimental model for cirrhosis in the rat. Br J Exp Pathol 1984;65:305-311.
28. Castaing D, Houssin D, Bismuth H. Orthotopic liver transplantation. Preparation of the removal of the graft from the donor. In: Castaing D, Houssin D Bismuth $\mathrm{H}$ (eds). Hepatic and portal surgery in the rat. Masson: Paris, 1980, pp 139-142.

29. Roskams T, Theise N, Balabaud C, et al. Nomenclature of the finer branches of the biliary tree: canals, ductules and ductular reactions in humans liver. Hepatology 2004;39:1739-1745.

30. Bedossa P, Poynard T. An algorithm for the grading of activity in chronic hepatitis C. The METAVIR cooperative study group. Hepatology 1996;24:289-293.

31. Hines J, Johnson S, Burt A. In vivo responses of macrophages and perisinusoidal cells to cholestatic liver injury. Am J Pathol 1993;142:511-518

32. Grinko I, Geerts A, Wisse E. Experimental biliary fibrosis correlates with increased numbers of fat-storing and Kupffer cells, and portal endotoxemia. J Hepatol 1995;23:449-458.

33. Kalinichenko V, Bhattacharyya D, Zhou Y, et al. Fos1 +/- mice exhibit defective stellate cell activation and abnormal liver regeneration following CCl4 injury. Hepatology 2003;37:107-117.

34. Mabuchi A, Mullaney I, Sheard P, et al. Role of hepatic stellate cell/hepatocyte interaction and activation of hepatic stellate cells in the early phase of liver regeneration in the rat. J Hepatol 2004;40:910-916.

35. Balabaud $C$, Bioulac-Sage $P$, Desmoulière $A$. The role of hepatic stellate cells in liver regeneration. J Hepatol 2004;40:1023-1026.

36. Sanz S, Pucilowska J, Liu S, et al. Expression of insulin-like growth factor I by activated hepatic stellate cells reduces fibrogenesis and enhances regeneration after liver injury. Gut 2005;54:134-141.

37. Tao L, Enzan H, Hayashi Y, et al. Appearance of denuded hepatic stellate cells and their subsequent myofibroblast-like transformation during the early stage of biliary fibrosis in the rat. Med Electron Microsc 2000;33:217-230.

38. Saile B, Matthes N, Neubauer K, et al. Rat liver myofibroblasts and hepatic stellate cells differ in CD95-mediated apoptosis and response to TNF-alpha. Am J Physiol 2002;283:G435-G444.

39. Saile B, Dirocco P, Dudas J, et al. IGF-I induces DNA synthesis and apoptosis in rat liver hepatic stellate cells (HSC) but DNA synthesis and proliferation in rat liver myofibroblasts (rMF). Lab Invest 2004;84:1037-1049.

40. Issa R, Zhou X, Constandinou C, et al. Spontaneous recovery from micronodular cirrhosis: evidence for incomplete resolution associated with matrix cross-link. Gastroenterology 2004;126: 1795-1808.

41. Carpino G, Morini S, Ginanni Corradini S, et al. Alpha-SMA expression in hepatic stellate cells and quantitative analysis of hepatic fibrosis in cirrhosis and in recurrent chronic hepatitis after liver transplantation. Dig Liver Dis 2005;37:349-356.

42. Degott C, Zafrani E, Callard P, et al. Histopathological study of primary biliary cirrhosis and the effect of ursodeoxycholic treatment on histology progression. Hepatology 1999;29:1007-1012.

43. Kinnman N, Housset C. Peribiliary myofibroblasts in biliary type liver fibrosis. Front Biosc 2002;7:496-503.

44. Kinnman N, Hultcrantz R, Barbu V, et al. PDGF-mediated chemoattraction of hepatic stellate cells by bile duct segments in cholestatic liver injury. Lab Invest 2000;80:697-707.

45. Couchie D, Lafdil F, Martin-Garcia N, et al. Expression and role of Gas6 protein and its receptor Axl in hepatic regeneration from oval cells in the rat. Gastroenterology 2005;129:1633-1642.

46. Lafdil F, Chobert M, Couchie D, et al. Induction of Gas6 protein in $\mathrm{CCl}_{4}$ induced rat liver injury and anti-apoptotic effect on hepatic stellate cells. Hepatology 2006;44:228-239.

47. Lafdil F, Deveaux V, Chobert M. Growth arrest-specific protein 6 (Gas6) promotes liver tissue repair after an acute toxic injury. J Hepatol 2006;44(Suppl 2):S135 (abstract).

48. Jhandier M, Kruglov E, Lavoie E, et al. Portal fibroblasts regulate the proliferation of bile duct epithelia via expression of NTPDase2. J Biol Chem 2005;280:22986-22992.

49. Murawaki $Y$, Ikuta $Y$, Idobe $Y$, et al. Tissue inhibitor of metalloproteinase- 1 in the liver of patients with chronic liver disease. J Hepatol 1997;26:1213-1219. 